\title{
SHOOT INITIATION AND MULTIPLICATION OF CORSICAN PINE IN VITRO
}

\author{
W.T.P.S.K. Senerath1, G.J. Mayhead'2, and D.S. Shaw2 \\ ${ }^{1}$ Department of Botany, University of Sri Jayewardenepura; \\ ${ }^{2}$ University of Wales, Bangor \\ (Based on a PhD thesis by W.T.P.S.K. Senerath submitted to the University of Wales)
}

\begin{abstract}
From different combinations of basal medium and growth regulators tested, it was found that the hest medium for producing shoots from mature embryos was $M S+2$ ppm BAP + 2 ppm NAA + $1.25 \mathrm{ppm} \mathrm{IBA;} \mathrm{from} \mathrm{apical} \mathrm{meristems;}{ }^{\circ} \mathrm{CD}+$ $1.12 \mathrm{ppm} \mathrm{BAP}+0.04 \mathrm{ppm} \mathrm{2,4-D}+0.01 \mathrm{ppm} \mathrm{K}$; and from needle fascicles, $(D)$ with no growth regulator. Of 3 substrates tested for growing seedlings to produce explants, the best (for apical-meristem explants) was low-nutrient compost, and the best age of seedling was 21 davs. Explants from one-year old plants and shoots produced in vitro gave more shoots than did those from mature trees; there was no significant difference in the length of the shoots: Production of adventitious buds for rapid multiplication was greater on explants of apical meristem origin than on those from mature embryos or needle fascicles; the percentage survival decreased significantly in second and third generations of explants of all three origins.
\end{abstract}

\section{Introduction}

Rapid multiplication is of interest not only for clonal propagation on a large commercial scale, but also as a potential means of gene-pool preservation (Jelaska, 1987). A problem in pines and other slow growing specics is the long time it takes to produce usable plants by traditional vegetative propagation, due to the low number of rootable cuttings obtained from each small plant per year. For many of the species clonal propagation by rooting cuttings is difficult, especially when the cuttings are taken from adult trees. Corsican pine (Pinus nigra var. maritima (Ait.) Melville) is an important plantation species in Europe. The objective of the investigation reported here was to develop tissue-culture techniques for the rapid multiplication of this species, which has a very slow growth rate and also a low rooting percentage. The techniques can also be used for the rapid propagation. or clonal propagation, of important forest trees in Sri Lanka.

\section{Materials and methods}

As the starting material for shoot initiation, mature embryos. apical meristems of young seedlings, and needle fascicles were used. They were washed in $10 \%$ hypochlorite solution, and then trimmed to get $2-5 \mathrm{~mm}$ explants. The prepared explants were dipped in $70 \%$ ethanol for $30 \mathrm{~s}$ and treated with $100 \mathrm{ppm} \mathrm{HgCl}_{2}$ for 3 minutes. After they had

\section{8}


becn rinsed three times in distilled water, they were blotted dry on sterile filter paper before being transferred onto the media. For cmbryo culture the seeds were washed, the seed coat was removed under stcrile conditions, and the cmbryos were excised. All the cultures were incubated at $26^{\circ} \mathrm{C}$. with a 16-hour day. A completely randomized design was used in all cxperiments, and the culture vessels were re-randomized at seven-day intervals.

\section{Experiment 1 - The best medium for shoot induction from different explant sources}

The explants were cultured in different basal media, in the presence of different growth regulators.Different basal media and growth regulators used in experiments are given in table 1. After five weeks a count was made of the percentage of explants producing shoots in each of the different media.

\section{Experiment 2 - The best substrate for growing seedlings to provide explants}

Secdlings were raised for 21 days in three different substrates, to provide apices for use as explants. The substrates were moist paper, low-nutrient compost, and sterile-water agar. After five weeks of incubation, a count was made of the number of explants from each source that produced shoots, and the shoot lengths were measured.

\section{Experiment 3 - The best seedling age to collect explants}

The best substrate for raising secdlings were determined from experiment 2. Apices were collected from seedlings grown in this substrate to different ages: $7,14,21$, and 28 days. After 5 weeks of incubation a count was made of the number of explants producing shoots. and the shoot lengths were measured.

\section{Experiment 4 - Shoot initiation from needle fascicles}

Needle fascicles from mature trees, from one-year-old plants, and from shoots produced in vitro were cultured in media in order to determine the rate of shoot initiation. After five weeks a count was made of the number of explants producing shoots, and the shoot lengths were measured.

\section{Experiment 5 - Shoot multiplication}

Forty shoots of each of three explant origins (mature cmbryos, apical meristems and needle fascicles) were cultured in a bud-induction medium to initiate adventitious buds. After six weeks a count was made of the number of adventitious buds per explant, and ten from each explant werc sub-cultured as the second generation. The same procedure was followed for a third generation. In each generation a count was made of the percentage survival, and of the number of adventitious buds per shoot. 
Annual Forestry Symposium, 1996

Table1: Different basal madia and growth regulators used

\begin{tabular}{ll}
\hline Basal media & Growth regulators \\
\hline Murashige and Skoog (MS) & IBA \\
Campbell and Dyrzan (CD) & BAP. NAA \\
Juglan's Medium (DKW) & $2,4-\mathrm{D}$ \\
Mc Cown Woody Plant Medium (WPM) & $\mathrm{GA}_{3}, \mathrm{~K}$ \\
\hline
\end{tabular}

\section{Results}

\section{Experiment 1}

On the different combinations of basal media and growth regulators that were tested, mature embryos showed the best shoot-initiation performance in $\mathrm{MS}+2.0 \mathrm{ppm} \mathrm{BAP}+$ 2.) $\mathrm{ppm} \mathrm{NAA}+1.25 \mathrm{ppm}$ IBA. The best medium for shoot initiation from apical meristems was CD +1.12 ppm BAP +0.04 ppm 2,4-D + 0.01 ppm K. For needle fascicles the best was $C D$ with no growth regulator (Table 2).

Table 2 : Shoot initiation in vitro from different explant sources in different culture media

\begin{tabular}{cccc}
\hline Medium & \multicolumn{3}{c}{ Pereentage of explants producing shoots } \\
& Mature embryos & Apical meristems & Necdle fascicles \\
\hline 1 & $50^{*}$ & 100 & 60 \\
2 & $75^{*}$ & 70 & 70 \\
3 & $45^{*}$ & 90 & 80 \\
\hline \multicolumn{2}{c}{ *callus production }
\end{tabular}

\section{Media}

$$
\begin{aligned}
& 1=\mathrm{CD}+1.12 \mathrm{ppm} \mathrm{BAP}+0.04 \mathrm{ppm} 2,4-\mathrm{D}+0.01 \mathrm{ppm} \mathrm{K} \\
& 2=\mathrm{MS}+2.0 \text { ppm BAP }+2.0 \mathrm{ppm} \mathrm{NAA}+1.25 \mathrm{ppm} \mathrm{IBA} \\
& 3=\mathrm{CD}, \text { no growth regulator }
\end{aligned}
$$

\section{Experiment 2}

The results of this experiment showed that there was a significant difference between the three substrates in the number of explants producing shoots. Although all the explants (20) out of 20 ) of apical meristems collected from seedlings raised on compost and water agar produced shoots. the apices collected from seedlings raised on compost gave statistically significantly greater shoot extension when compared with the other two substrates. As Table 3 shows, therefore, low-nutrient compost is the best of these three substrates for raising seedlings to provide apices for shoot initiation. 
Senarath

Table 3 : Effect of different seedling substrates on shoot initiation from apical meristems

\begin{tabular}{lcc}
\hline Secdling substrate & $\begin{array}{c}\text { Number of explants producing } \\
\text { shoots }\end{array}$ & $\begin{array}{c}\text { Mean shoot length } \\
(\mathbf{m m})\end{array}$ \\
\hline Moist paper & 12 & 14.1 \\
Compost & 20 & 22.5 \\
Water agar & 20 & 7.1 \\
\hline
\end{tabular}

\section{Experiment 3}

There were significant differences in the number of explants producing shoots and in the mean shoot length according to the age of the seedlings. Very young seedlings (7 days) produced only callus: there was no shoot clongation. The mean shoot length increased up to 21 -day secdling age, and declined at 28 days (Table 4).

Table 4: Effect of seedling age on shoot initiation in vitro from apical meristems

Age of secdling

\begin{tabular}{ccc} 
& producing shoots & $(\mathbf{m m})$ \\
\hline 7 & callus only & - \\
14 & 17 & 7.2 \\
21 & 20 & 21.8 \\
28 & 14 & 15.4 \\
\hline
\end{tabular}

\section{Experiment 4}

The age of the source of the explant had a significant effect on shoot initiation from needle fascicles. Between the three different origins there was a significant difference in the number of explants producing shoots, but not in the mean shoot length. Needle fascicles produced in vitro had a greater tendency to initiate sloots than those from plants which were more than one-year-old (Table 5).

Table 5 :Shoot initiation from needle fascicles

\begin{tabular}{lcc}
\hline \multicolumn{1}{c}{ Source of explant } & $\begin{array}{c}\text { Number of explants } \\
\text { producing shoots }\end{array}$ & $\begin{array}{c}\text { Mean shoot length } \\
\text { ( } \mathbf{m m} \text { ) }\end{array}$ \\
\hline Mature trees & 8 & 5.20 \\
Onc-ycar-old plants & 20 & 5.65 \\
Shoots produced in vitro & 20 & 6.24 \\
\hline
\end{tabular}

\section{Experiment 5}

For all three origins (mature embryo, apical meristem and needle fascicle) an apparent reduction in the mean number of shoots per generation was not significant. The overall mean for the number of buds per shoot was significantly greater for shoots of apical meristem origin. The percentage sunival decreased significantly for all three origins from the first to the third generation (Table 6). 
Table $6:$ Mean number of adventitious buds per shoot (and percentage survival) after 18 weeks, i.e. three generations of six weeks each

\begin{tabular}{cccc}
\hline Generation & Mature embryo & Apical meristem & Needle fascicle \\
\hline 1 & $1.20(100 \%)$ & $2.75(100 \%)$ & $1.55(100 \%)$ \\
2 & $1.73(87.6 \%)$ & $1.73(89.8 \%)$ & $1.46(86.4 \%)$ \\
3 & $0.90(75.5 \%)$ & $1.40(80.6 \%)$ & $1.20(0.11 \%)$ \\
\hline
\end{tabular}

\section{Discussion}

\section{Seedling substrate}

The main problem in using non-sterile substrates was contamination of the cultures. Subjectively, there was also a visual difference between seedlings grown on different substrates. Seedlings grown on compost were dark green in colour and more robust. perhaps because of nutrients present in it. Seedlings from moist paper, which had no nutrients added. were more tender. The seedlings in water agar were of a tighter green and weaker in appearance. Tranvan (1979) has reported a correlation between the growth of the parent plants and callus production from the explants.

\section{Seedling age}

The length of the shoots produced from meristem explants increased up to a seedling age of 21 days, and then declined. In contrast to the above results, Zel et al. (1988) found that explants from seedlings of different ages (three, six, and nine weeks) did not display a wide range of variation in their shoot elongation, but did vary more in adventitious bud formation.

\section{Needle fascicle culture}

Needle fascicles from younger plants had a greater tendency to initiate shoots than those from mature plants. Jasson \& Borman (1981) similarly found that bud induction in needle explants of Picea abies was greatly affected by needle agc. Von Arnold \& Eriksson (1979) obtained good results with Picea abies needle explants collected just after the bud flush.

\section{Shoot multiplication}

Tranvan (1979) attempted to induce adventitious bud formation at the apex of very young Pinus sylvestris seedlings. Although multiple buds were formed, it was not clear whether bud induction was occurring directly at the seedling apex, on the cotyledons, or on internodal tissue. Webb (1978) found that in Pinus contorta apices several of the adventitious shoots started to grow but only one or two continued to extend. No records 
were found in the literature on the decline of survival ability from one generation to the other, but it can be explained by the decreasing totipotency of cells with time.

\section{References}

Arnold, S. von and Eriksson, T. (1979). Bud induction on isolated needles of Picea abies grown in vitro. Plant Science Letters 15, 363-372.

Jasson, E. and Bornman, C.H. (1981). In vitro initiation of adventitious structures in relation to the abscission zone in needle explants of Picea abies - anatomical considerations. Physiologia Plantarum 53,191-197.

Jelaska, S. (1987). European pines. In J.M. Bonga and Durzan (Eds.), Cell and tissue culture in forestry. Netherlands, Martinus Nijhoff. Pp. 42-60.

Senarath, W.T.P.S.K (1996) In vitro propagation of Pinus nigra var. maritima (Corsican pine). Ph.D Thesis, University of Wales, Bangor, UK

Tranvan. H. (1979). In vitro adventitious bud formation on isolated seedlings of Pinus sylvestris. Biologia Plantarum 21, 230-233.

Webb. K.J. (1978). (irowth and morphogenesis of tissue cultures of Picea sitchensis and Pinus contorta. PhD thesis, University of Leicester.

Zel, J.. Gogala. N. and Camloh, M. (1988). Micropropagation of Pimus sylvestris. Plant Cell iissue anci Organ Culture 14. 169-175. 